\title{
Reduced expression of $\alpha$-catenin, $\beta$-catenin, and $\gamma$-catenin is associated with high cell proliferative activity and poor differentiation in non-small cell lung cancer
}

\author{
R T Pirinen, P Hirvikoski, R T Johansson, S Hollmén, V-M Kosma
}

Departments of Pathology and Forensic Medicine, University of Kuopio and Kuopio University Hospital, PO Box 1627, FIN-70211 Kuopio,

Finland

R T Pirinen

V-M Kosma

Department of Pathology, Centre for Laboratory Medicine, Tampere University Hospital, PO Box 2000, FIN-33521 Tampere,

Finland

P Hirvikoski

Department of Oncology, University of Kuopio and Kuopio University Hospital

$\mathrm{R} T$ Johansson

Department of Pathology, Satakunta Central Hospital, FIN-28500 Pori,

Finland

S Hollmén

Correspondence to: Dr Kosma

Velimatti.Kosma@uku.fi

Accepted for publication 9 November 2000

\begin{abstract}
Aims-To investigate the expression of catenins $(\alpha, \beta$, and $\gamma)$ in non-small cell lung carcinoma (NSCLC) and its relation to clinicopathological factors and prognosis. Methods-The expression of catenins was analysed immunohistochemically in 261 patients with resected NSCLC, diagnosed between 1978 and 1996 in eastern Finland. The cell proliferation index of the tumours was analysed by means of an image analyser. The staining results were compared with clinicopathological characteristics and survival.
\end{abstract}

Results-Normal catenin staining was found significantly more often in adenocarcinomas than in squamous cell carcinomas or anaplastic/large cell carcinomas. Reduced staining of $\alpha$-catenin, $\beta$-catenin, and $\gamma$-catenin was related to poor differentiation of the tumour. The tumours with reduced staining of $\beta$-catenin or $\gamma$-catenin often had higher cell proliferation activity. Nuclear staining of $\beta$-catenin and $\gamma$-catenin was found in $16(7 \%)$ and $29(13 \%)$ cases, respectively. This nuclear staining correlated directly with increased cell proliferation and inversely with membranous staining. In survival analyses the predictors of overall and disease free survival were stage and tumour type. The expression of catenins did not affect survival.

Conclusions-The expression of $\alpha$-catenin, $\beta$-catenin, and $\gamma$-catenin is related to histological type and differentiation in NSCLC, although catenins have no independent prognostic value. However, this study supports the important role of the nuclear accumulation of $\beta$-catenin and $\gamma$-catenin in highly proliferative cells.

(F Clin Pathol 2001;54:391-395)

Keywords: catenin; lung cancer; proliferation; differentiation

E-cadherin-catenin complexes regulate the functional integrity of the epithelium by mediating specific intercellular adhesion. ${ }^{1}$ The cytoplasmic domain of E-cadherin forms complexes with $\beta$-catenin or $\gamma$-catenin, which in turn bind to $\alpha$-catenin, which anchors the complex to the cytoskeleton. The presence of all catenins is essential for the full adhesive function of the cell. In addition, catenins are also involved in cell proliferation, differentiation, and migration. ${ }^{2}$
$\alpha$-Catenin might serve as an invasion suppressor molecule, and reduced expression of $\alpha$-catenin has been related to poor differentiation of tumours, infiltrative growth, and lymph node metastasis. ${ }^{3}$ Furthermore, the disappearance of membranous $\alpha$-catenin is predictive of an unfavourable outcome in prostate, ovarian, and colorectal cancer. ${ }^{4-6}$ Similarly, reduced $\beta$-catenin expression is related to poor differentiation and more aggressive tumour growth, ${ }^{7}$ although not all reports are in agreement. ${ }^{389}$ $\beta$-Catenin forms a complex with the adenomatous polyposis coli (APC) protein, which is mutated in most human colon cancers. ${ }^{10}$ As a consequence, $\beta$-catenin expression has been observed in the nucleus and the cytoplasm, instead of the usual localisation on the cell membrane. ${ }^{10}$ Cytoplasmic or nuclear accumulation of $\beta$-catenin seems to be associated with the progression of colorectal and oesophageal cancers. ${ }^{11}{ }^{12}$ Although the role of $\gamma$-catenin in cadherin-catenin complex formation is not firmly established, it has been shown that the association of E-cadherin with $\alpha$-catenin and $\beta$-catenin is not sufficient to modify the behaviour of highly malignant cells, and $\gamma$-catenin is essential in this context. ${ }^{13}$ Altered expression of $\gamma$-catenin has been correlated with shortened survival in patients with bladder cancer. ${ }^{14}$ However, its role in the progression and differentiation of many tumours is not clear.

Lung cancer is still a leading cause of death in men. ${ }^{15}$ To date, despite an active search for new prognostic biomarkers, the stage of disease is still the most valuable prognostic factor in non-small cell lung cancer (NSCLC). ${ }^{16}$ The few studies concerning the prognostic role of catenins in NSCLC have found the reduced expression of $\beta$-catenin and $\gamma$-catenin to be associated with an unfavourable outcome. ${ }^{17} 18$ However, correlations with other clinicopathological factors have not been found. ${ }^{17}{ }^{19}$ Therefore, we studied the expression of all three catenins $(\alpha, \beta$, and $\gamma)$ in a large sample of resected NSCLC specimens and compared the results with the clinicopathological features and survival of the patients.

\section{Materials and methods}

PATIENTS AND FOLLOW UP

The study population comprised 261 patients with resected NSCLC treated in eastern Finland from 1978 to 1996 (table 1). There were 239 men and 22 women in the study cohort. The mean age of the patients was 63 years. Most patients (222) underwent either 
Table 1 Clinicopathological characteristics of the patients

\begin{tabular}{lc}
\hline Sex & \\
Male & $239(92 \%)$ \\
Female & $22(8 \%)$ \\
Age & \\
$<60$ years & $95(36 \%)$ \\
$\geqslant 60$ years & $166(64 \%)$ \\
Histology & \\
Total & 261 \\
Squamous cell carcinoma & $163(63 \%)$ \\
Adenocarcinoma & $68(26 \%)$ \\
Anaplastic/large cell carcinoma & $30(11 \%)$ \\
Histological grade & \\
Grade I & $18(7 \%)$ \\
Grade II & $106(41 \%)$ \\
Grade III & $95(36 \%)$ \\
Not assessed (anaplastic/large cell carcinoma) & $30(12 \%)$ \\
Data missing & $12(4 \%)$ \\
Karnofsky scale & \\
$<70$ & $17(7 \%)$ \\
$\geqslant 70$ or more & $236(90 \%)$ \\
Not known & $8(3 \%)$ \\
Stage & \\
Stage I & $166(64 \%)$ \\
Stages II-IV & $89(34 \%)$ \\
Not assessed & $6(2 \%)$ \\
Smoker & \\
Yes & $219(84 \%)$ \\
No & $5(2 \%)$ \\
Data missing & $35(14 \%)$ \\
Recurrence during the follow up & \\
Yes & $124(48 \%)$ \\
No & $137(52 \%)$ \\
Radical pulmectomy/lobectomy & \\
Palliative pulmectomy/lobectomy & $222(85 \%)$ \\
Explorative thoracotomy & $26(10 \%)$ \\
& $13(5 \%)$ \\
\hline
\end{tabular}

radical lobectomy ( $50 \%$ of cases) or pneumonectomy ( $35 \%$ of cases). Palliative resection was performed in $10 \%$ of the patients and explorative thoracotomy only in $5 \%$ of the patients. None of the patients received radiotherapy or chemotherapy before surgery. Postoperative radiotherapy was given to 61 patients and chemotherapy to 11 . TNM classification and stage of the disease ${ }^{20}$ were determined by reviewing radiological examinations, findings during surgery, and the histopathological evaluation of the tumour. Follow up was performed regularly by a senior physician according to routine protocol. All clinical data were collected retrospectively by reviewing the patients' files.

HISTOPATHOLOGICAL EVALUATION

The histological diagnosis and grade of differentiation were re-evaluated (V-MK and $\mathrm{SH}$ ) using haematoxylin and eosin stained sections according to the WHO classification. ${ }^{21}$ There were 163 squamous cell carcinomas, 68 adenocarcinomas, and 30 anaplastic/large cell carcinomas in our study. The most representative slide was used in the immunohistochemical analyses.

\section{IMMUNOHISTOCHEMISTRY}

Catenins

Briefly, the paraffin wax embedded samples were cut into $5 \mu \mathrm{m}$ thick sections and dewaxed in graded alcohols. For the antigen retrieval, the sections were heated in a microwave oven for three periods of five minutes in Tris/ $\mathrm{HCl}$ buffer, pH 9.7 ( $\alpha$-catenin), or citrate buffer, pH 6.0 ( $\beta$-catenin and $\gamma$-catenin). The slides were washed with phosphate buffered saline (PBS) for two times five minutes and endogeneous peroxidase activity was blocked by $5 \%$
$\mathrm{H}_{2} \mathrm{O}_{2}$ for five minutes. The sections were washed twice with PBS and treated with $1.5 \%$ normal serum (ABC Elite kit; Vector, Burlingame, California, USA). The primary antibody (Transduction Laboratories, Lexington, Kentucky, USA) was used at a dilution of $1 / 200$ (in $1 \%$ bovine serum albumin in PBS ( $\alpha$-catenin), $1 / 1000$ ( $\beta$-catenin), or $1 / 100$ ( $\gamma$-catenin). Slides were incubated overnight at $4^{\circ} \mathrm{C}$, washed with PBS, and treated with the biotinylated secondary antibody and avidin-biotin peroxidase reagent (Vector). Diaminobenzidine was used as a chromogen. The slides were washed with PBS, lightly counterstained with haematoxylin, dehydrated, cleared, and mounted in Depex (PDH, Poole, Dorset, UK). A sample of normal colonic mucosa, known to be positive for all catenins, was used as a positive control. In the negative controls, the same samples were stained without adding the primary antibody.

Ki-67

To determine the proliferative activity of the tumour, anti-Ki-67 (MIB1; Immunotech, Marseille, France) was used as a primary antibody, diluted $1 / 200$. The indirect ABC technique was used as described above.

EVALUATION OF STAINING

All samples were evaluated (RP, $\mathrm{PH}$, and $\mathrm{V}-\mathrm{MK}$ ) unaware of the clinical data. In the case of disagreement (less than 10\% of the cases) the slides were reviewed again and a consensus was reached. The staining reaction localised on the cell membranes was graded into three groups according to the percentage of the positively stained carcinoma cells as follows: $<10 \%, 10-90 \%$, and $\geqslant 90 \%$ of the tumour cells showing a positive staining pattern. Tumours showing $90 \%$ or more positively stained cells were categorised as normally stained, others were classified as reduced. ${ }^{22}$ Nuclear staining of $\beta$-catenin and $\gamma$-catenin was recorded as positive or negative. In positive samples nuclear staining was seen in more than $20 \%$ of cancer cells.

For the Ki-67 staining, the percentage of the stained nuclei (proliferation index; PI) was determined by a continuous scale using the CAS 200 (Becton Dickinson, Elmhurst, Illinois, USA) image analyser as described previously. ${ }^{23}$ The data were available for analysis from datasheets of our previous study. ${ }^{24}$

\section{STATISTICAL ANALYSIS}

SPSS version 8.0 was used in the analyses. The Mantel-Haenzel or Pearson $\chi^{2}$ test, when appropriate, was used to clarify the relation between staining results and other variables studied. The cell proliferation associated with catenins was analysed with Kruskall-Wallis and Mann-Whitney U tests. Overall (OS) and disease free survival (DFS) were estimated by means of the Kaplan-Meier test and Cox's multivariate hazards model. In DFS analyses only the patients who were treated with radical resection of tumour were included. Deaths by any other cause than lung cancer were considered as censored events-corrected survival rates were used. 
Table 2 Distribution of staining of different catenins as related to clinicopathological factors

\begin{tabular}{|c|c|c|c|c|c|c|c|c|c|c|c|c|c|c|c|}
\hline & \multicolumn{5}{|c|}{ a-Catenin } & \multicolumn{5}{|c|}{$\beta$-Catenin } & \multicolumn{5}{|c|}{$\gamma$-Catenin } \\
\hline & $<10 \%$ & $\begin{array}{l}10- \\
90 \%\end{array}$ & $\geqslant 90 \%$ & $N$ & $p$ Value & $<10 \%$ & $\begin{array}{l}10- \\
90 \%\end{array}$ & $\geqslant 90 \%$ & $N$ & $p$ Value & $<10 \%$ & $\begin{array}{l}10- \\
90 \%\end{array}$ & $\geqslant 90 \%$ & $N$ & $p$ Value \\
\hline \multicolumn{16}{|l|}{ Histology } \\
\hline $\begin{array}{l}\text { Squamous cell } \\
\text { carcinoma }\end{array}$ & 24 & 49 & 27 & 146 & & 16 & 69 & 15 & 145 & & 15 & 64 & 21 & 146 & \\
\hline Adenocarcinoma & 5 & 33 & 62 & 58 & $<0.0001$ & 10 & 24 & 66 & 58 & $<0.0001$ & 13 & 29 & 58 & 59 & $<0.0001$ \\
\hline $\begin{array}{l}\text { Anaplastic/large cell } \\
\text { carcinoma } \\
\text { Histological grade }\end{array}$ & 37 & 41 & 22 & 27 & & 23 & 58 & 19 & 26 & & 43 & 42 & 15 & 26 & \\
\hline Grade I & 20 & 20 & 60 & 15 & & 6 & 44 & 50 & 16 & & 6 & 38 & 56 & 16 & \\
\hline Grade II & 11 & 47 & 42 & 96 & 0.005 & 12 & 54 & 34 & 94 & 0.007 & 9 & 58 & 33 & 96 & 0.005 \\
\hline $\begin{array}{l}\text { Grade III } \\
\text { Stage }\end{array}$ & 25 & 48 & 27 & 88 & & 18 & 60 & 22 & 87 & & 21 & 53 & 26 & 85 & \\
\hline Stage I & 19 & 43 & 38 & 146 & & 16 & 56 & 28 & 149 & & 16 & 53 & 31 & 147 & \\
\hline Stage II-IV & 24 & 47 & 29 & 81 & 0.6 & 15 & 55 & 30 & 76 & 0.2 & 20 & 52 & 28 & 80 & 0.6 \\
\hline Tumour size & & & & & & & & & & & & & & & \\
\hline $\mathrm{T} 1$ & 18 & 39 & 43 & 61 & & 14 & 49 & 37 & 63 & & 18 & 49 & 33 & 63 & \\
\hline $\begin{array}{l}\mathrm{T} 2-4 \\
\text { Lymph node status }\end{array}$ & 21 & 46 & 33 & 165 & 0.4 & 16 & 60 & 24 & 161 & 0.2 & 17 & 54 & 29 & 164 & 0.8 \\
\hline NO & 19 & 44 & 37 & 154 & & 15 & 58 & 27 & 156 & & 15 & 55 & 30 & 154 & \\
\hline N1-3 & 24 & 44 & 32 & 72 & 0.6 & 16 & 53 & 31 & 68 & 0.7 & 22 & 48 & 30 & 73 & 0.4 \\
\hline
\end{tabular}

Numbers are percentages of cases identified in the three groups: $<10 \% ; 10-90 \%$; $\geqslant 90 \%$.

ETHICS

Our study plan was approved by the ethical committee of the Kuopio University Hospital and the Finnish Ministry of Social Affairs and Health.

\section{Results}

Two hundred and thirty one samples were immunostained successfully for $\alpha$-catenin, 229 for $\beta$-catenin, and 231 for $\gamma$-catenin. Some samples were discarded because of technical problems, such as partial folding of the tissue section or lack of invasive carcinoma in the section. The distribution of clinicopathological characteristics (stage, sex, grade, Karnofsky scale, histological type of tumour) among the patients with tissue samples for immunohistochemistry did not differ from the original

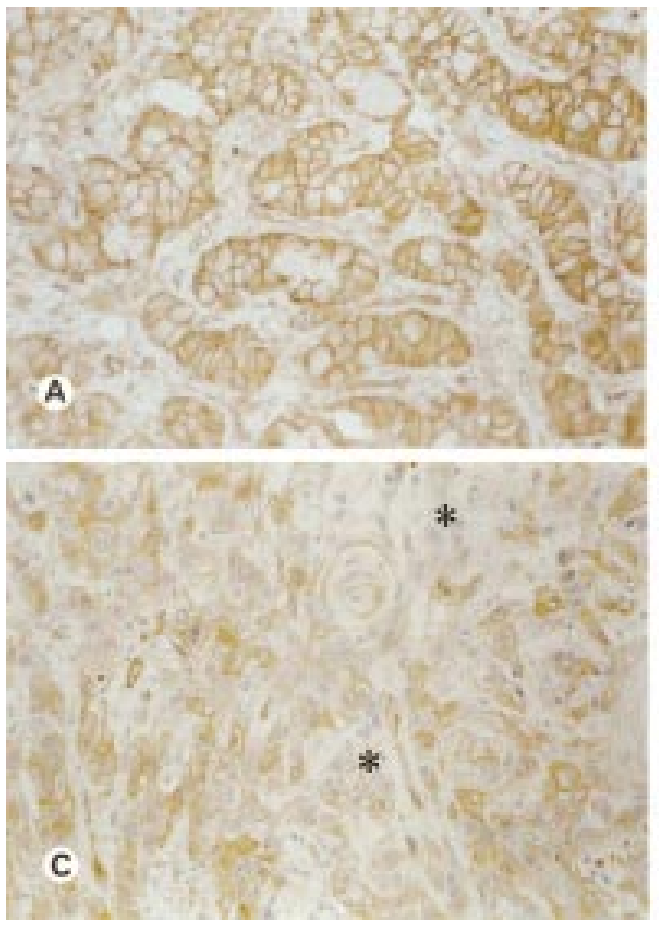

patient group $(n=261)$. Benign bronchial glands showed normal staining patterns for $\alpha$-catenin, $\beta$-catenin, and $\gamma$-catenin. In addition, normal staining reactions for all catenins were found in the bronchial pseudostratified columnar epithelium and basal cells.

STAINING OF CATENINS AND

CLINICOPATHOLOGICAL PARAMETERS

Table 2 summarises the results. Normal staining for $\alpha$-catenin, $\beta$-catenin, and $\gamma$-catenin was found significantly more often in adenocarcinomas $(62 \%, 66 \%$, and $58 \%$ of cases, respectively) than in squamous cell or anaplastic/large cell carcinomas ( $p<0.0001$ for all; fig $1 \mathrm{~A}$ and B; table 2). Poorly differentiated tumours more often showed reduced staining for all catenins ( $p=0.005, p=0.007$, and $p=0.005$ for
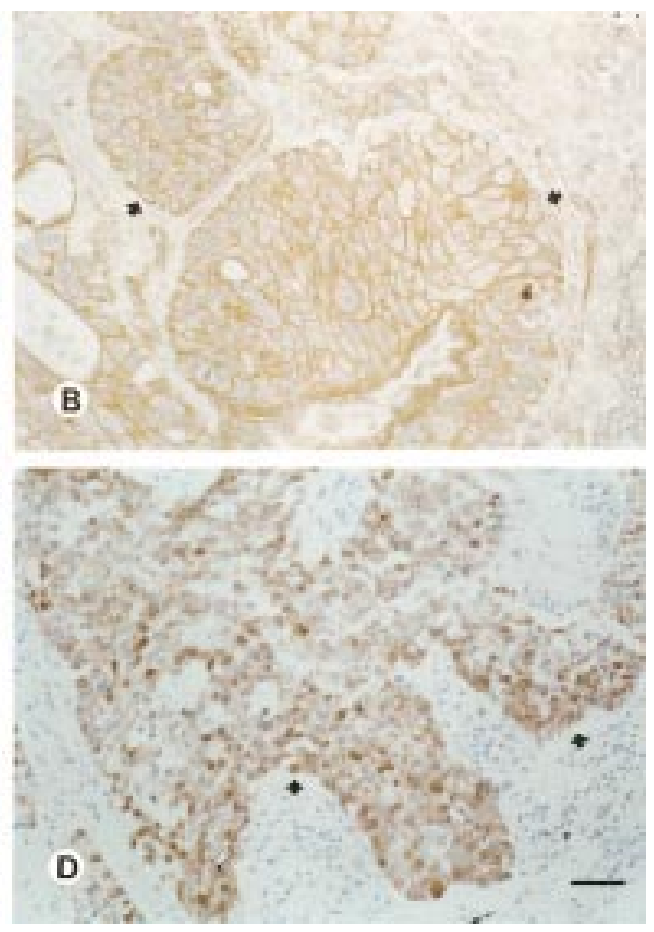

Figure 1 (A) Normal $(\geqslant 90 \%)$ membranous expression of a-catenin in bronchial adenocarcinoma. (B) Normal expression (arrows) of a-catenin in squamous cell carcinoma. (C) Reduced expression $(<90 \%$, asterisks) of $\beta$-catenin in squamous cell carcinoma. (D) Nuclear expression (arrows) of $\beta$-catenin in poorly differentiated squamous cell carcinoma. Bar, $50 \mu \mathrm{m}$. 


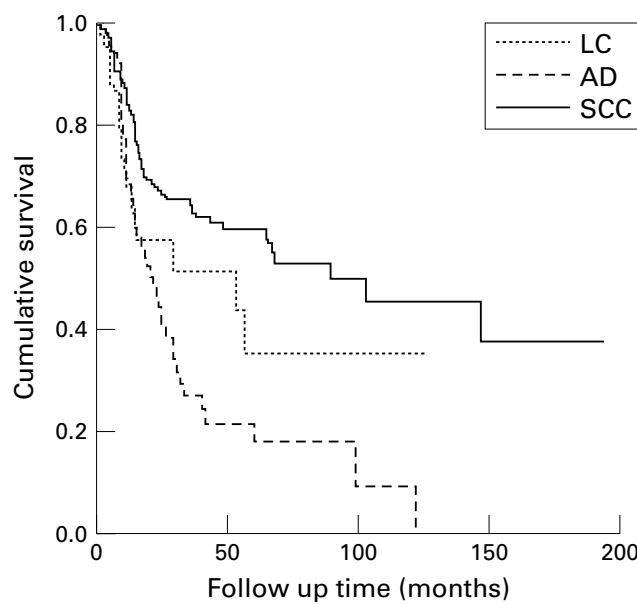

Figure 2 In disease free survival analysis there was a significant difference in survival between different histological subtypes of non-small cell lung carcinoma $(p=0.0001) . A D$, adenocarcinoma; LC, large cell/anaplastic carcinoma; SCC, squamous cell carcinoma.

$\alpha$-catenin, $\beta$-catenin, and $\gamma$-catenin, respectively; fig 1C). Nuclear staining of $\beta$-catenin and $\gamma$-catenin was found in $16(7 \%)$ and 29 $(13 \%)$ cases, respectively, and was seen more often in squamous cell carcinomas (11 cases with $\beta$-catenin and 24 cases with $\gamma$-catenin) than in adenocarcinomas or anaplastic/large cell carcinomas. Nuclear staining correlated inversely with the membranous staining pattern $(\mathrm{p}=0.001$ and $\mathrm{p}=0.0003$, respectively; fig 1D).

CELL PROLIFERATION

Tumours with reduced $\beta$-catenin or $\gamma$-catenin staining had higher PI values $(\mathrm{p}=0.0001$ for $\beta$-catenin; $p=0.006$ for $\gamma$-catenin) than did those with a normal staining pattern. Furthermore, nuclear positivity for $\beta$-catenin and $\gamma$-catenin was associated with a higher PI ( $\mathrm{p}=0.01$ and $\mathrm{p}=0.002$, respectively). $\alpha$-Catenin staining was not related to cell proliferation. Moreover, PI was associated with tumour type $(\mathrm{p}=0.001)$ and grade $(\mathrm{p}=0.004)$.

\section{SURVIVAL ANALYSIS}

At the end of follow up $136(52.1 \%)$ patients had died of lung cancer and $56(21.5 \%)$ were alive. A recurrent tumour was noted in 124 cases $(47.5 \%)$ during follow up. In univariate survival analysis, more advanced stage (II-IV) was a sign of poor OS $(\mathrm{p}=0.0006)$. Patients with adenocarcinoma or large cell/anaplastic carcinoma had poorer OS than did patients with squamous cell carcinoma $(p=0.0003)$. Similarly, the stage $(p=0.006)$ and histological type of the tumour $(\mathrm{p}=0.0001)$ significantly predicted DFS (fig 2). The expression of catenins did not predict survival. In Cox's multivariate analysis including stage and histological type of tumour, both retained their independent prognostic value to predict OS and DFS ( $p<0.0005$ for both).

\section{Discussion}

Alterations in E-cadherin-catenin complexes act as an important link in the progression of different cancers. ${ }^{13}$ Lung cancer is the most frequent cancer worldwide, and despite some downward trends in mortality prognosis remains poor. ${ }^{15}$ Few studies have investigated the prognostic value of catenins in lung cancer. ${ }^{18} 19$ In our present study, we investigated the distribution of different catenins in a large population of patients with resected NSCLC. Altered expression of catenins was found to correlate with the tumour type, with anaplastic/large cell and squamous cell carcinomas more often showing reduced staining of all catenins compared with adenocarcinomas. In addition, reduced staining of catenins was often seen in poorly differentiated tumours. Furthermore, nuclear staining of $\beta$-catenin and $\gamma$-catenin was related to increased proliferative activity of the tumour.

The distribution of catenins seems to be related to tumour type. Previous results indicate that lung adenocarcinomas often show normal staining for catenins, which supports our observations. ${ }^{19}$ Squamous cell carcinomas at different localisations show variable staining of catenins, although staining is mostly reduced..$^{22} 26$ In many human cancers, reduced expression of $\alpha$-catenin and $\beta$-catenin has been associated with poor tumour differentiation, ${ }^{27-29}$ which is in line with our present study. In addition, lack of expression of $\alpha$-catenin and $\beta$-catenin has been shown to correlate with a more advanced stage in laryngeal, ovarian, and bladder cancers. ${ }^{527}$ In NSCLC, reduced expression of E-cadherin has been associated with increased lymph node metastases, ${ }^{30}$ but the expression of $\alpha$-catenin and $\gamma$-catenins has not been related to TNM classification of the tumour, ${ }^{17}{ }^{19}$ a finding that is supported by our study.

In our study, increased proliferative activity of the tumour was associated with reduced expression of $\beta$-catenin and $\gamma$-catenin. This supports the theory that a reduction in the expression of catenins is a sign of more aggressive tumour behaviour. ${ }^{3}$ However, a similar relation between cell proliferation and reduced expression of catenins was not found in some previous studies. ${ }^{51}$ Furthermore, the tumours in our series that showed nuclear $\beta$-catenin staining also had significantly higher PI values. According to recent studies, the nuclear accumulation of $\beta$-catenin is a consequence of the disturbance of the system that normally degrades cytosolic $\beta$-catenin. ${ }^{10} \quad$ Nuclear $\beta$-catenin interacts with the Wnt/lef transcription pathway, resulting in changes in gene expression and cell differentiation during the malignant process. ${ }^{10}$ Recently, Nhieu and colleagues $^{32}$ found an association between cell proliferation and nuclear accumulation of $\beta$-catenin in hepatocellular carcinoma, which is in agreement with our findings. Interestingly, we found that nuclear staining of $\gamma$-catenin was also related to increased cell proliferation. However, the role of $\gamma$-catenin in these regulatory events remains unclear.

Nuclear staining of $\beta$-catenin has been linked with clinicopathological factors in some previous studies. ${ }^{11}$ In particular, increased 
nuclear staining of $\beta$-catenin has been demonstrated in colorectal carcinoma, being predominantly located at the invasion front. ${ }^{11}$ This suggests a role for nuclear $\beta$-catenin in tumour cell migration and invasion. In addition, the nuclear accumulation of $\beta$-catenin was related to unfavourable prognosis in pharyngeal cancer. ${ }^{33}$ In our study, we found no correlation between nuclear staining and clinicopathological parameters or survival. One explanation for these results might be the relatively low number of cases included in the analysis. However, other studies on carcinomas have found no evidence of nuclear accumulation of $\beta$-catenin or have questioned the clinical prognostic value of nuclear staining. ${ }^{11}{ }^{114}$ It seems that the expression of nuclear $\beta$-catenin might be tumour type dependent, and studies with a larger number of positive cases are needed to clarify its clinicopathological value.

The loss of expression of catenins has been related to an unfavourable outcome in many human cancers, ${ }^{4522}$ although conflicting data also exist. ${ }^{35}$ In NSCLC, reduced expression of $\beta$-catenin and $\gamma$-catenin has been related to poor prognosis, ${ }^{17}{ }^{18}$ which contradicts our data. One explanation for our divergent results could be the relatively high number of recurrences noted in the adenocarcinomas. However, the analyses within the histological subgroups did not change the results.

Taken together, we have shown that the expression of different catenins $(\alpha, \beta$, and $\gamma)$ in NSCLC is related to the histological type and differentiation of the tumour. Furthermore, our study supports the important role of $\beta$-catenin and $\gamma$-catenin in regulating the proliferative activity of the tumour. However, we found no association between the catenins and the other clinicopathological parameters and survival. We conclude that catenins play an important role in regulating the behaviour of NSCLC, although they have no independent clinical prognostic value beyond the well known factors affecting the survival of patients.

This study was supported by EVO funds from the Kuopio University Hospital. Financial support was also received from Savon Syöpärahasto and from the Research Foundation of ORION
Corporation, Finland. The technical assistance of Mrs A Parkkinen, Ms R Eskelinen, and Ms H Kemiläinen is gratefully acknowledged.

1 Pötter E, Bergwitz C, Brabant G. The cadherin-catenin system: implications for growth and differentiation of tem: implications for growth and differen

2 Jankowski JA, Bruton R, Shepherd N, et al. Cadherin and catenin biology represent a global mechanism for epithelial cancer progression. Mol Pathol 1997;50:289-90.

3 Shiozaki H, Oka H, Inoue $M$, et al. E-cadherin mediated adhesion system in cancer cells. Cancer 1996;77:1605-13.

4 Aaltomaa S, Lipponen P, Ala-Opas M, et al. Alpha-catenin expression has prognostic value in local and locally advanced prostate cancer. Br f Cancer 1999;80:477-82.

5 Anttila M, Kosma VM, Ji H, et al. Clinical significance of alpha-catenin, collagen IV, and Ki-67 expression in epithelial ovarian cancer. $\mathcal{F}$ Clin Oncol 1998;16:2591-600.

6 Raftopoulos I, Davaris P, Karatzas G, et al. Level of alpha-catenin expression in colorectal cancer correlates with invasiveness, metastatic potential, and survival. F Surg Oncol 1998;68:92-9.

7 Hashizume R, Koizumi H, Ihara A, et al. Expression of beta-catenin in normal breast tissue and breast carcinoma: a comparative study with epithelial cadherin and alphacatenin. Histopathology 1996;29:139-46.
8 Andrews NA, Jones AS, Helliwell TR, et al. Expression of the E-cadherin-catenin cell adhesion complex in primary the E-cadherin-catenin cell adhesion complex in primary nodal metastases. Br f Cancer 1997;75:1474-80.

9 Dillon DA, D'Aquila T, Reynolds AB, et al. The expression of p120ctn protein in breast cancer is independent of alpha- and beta-catenin and E-cadherin. Am F Pathol 1998; 152:75-82.

10 Bullions LC, Levine AJ. The role of beta-catenin in cell adhesion, signal transduction, and cancer. Curr Opin Oncol 1998;10:81-7.

11 Brabletz T, Jung A, Hermann K, et al. Nuclear overexpression of the oncoprotein beta-catenin in colorectal cancer is localized predominantly at the invasion front. Pathol Res Pract 1998;194:701-4.

12 Kimura Y, Shiozaki H, Doki Y, et al. Cytoplasmic beta-catenin in esophageal cancers. Int $\mathcal{F}$ Cancer 1999;84: $174-8$.

13 Nollet F, Berx G, van Roy F. The role of the E-cadherin/ catenin adhesion complex in the development and progression of cancer. Mol Cell Biol Res Commun 1999;2:77-85.

14 Syrigos KN, Harrington K, Waxman J, et al. Altered gamma-catenin expression correlates with poor survival in patients with bladder cancer. $\mathcal{F}$ Urol 1998;160:1889-93.

15 Franceschi S, Bidoli E. The epidemiology of lung cancer. Ann Oncol 1999;10:3-6.

16 Patz EF. Imaging lung cancer. Semin Oncol 1999;26:21-6.

17 Pantel K, Passlick B, Vogt J, et al. Reduced expression of plakoglobin indicates an unfavorable prognosis in subset of patients with non-small cell lung cancer. $\mathcal{F}$ Clin Oncol 1998; 16:1407-13.

18 Retera JM, Leers MP, Sulzer MA, et al. The expression of beta-catenin in non-small-cell lung cancer: a clinicopathobeta-catenin in non-small-cell lung cancer:
logical study. 7 Clin Pathol 1998;51:891-4.

19 Smythe WR, Williams JPWMJ, Johnson KR, et al. Cadherin and catenin expression in normal human bronchial epithelium and non-small cell lung cancer. Lung Cancer 1999;24: $157-68$.

20 UICC. In: Sobin LH, Wittekind C, eds. TNM classification of malignant tumours, 5th ed. New York: Wiley-Liss, 1997.

21 Travis WD, Colby TV, Corrin B, et al. Histological typing of lung and pleural tumours. Berlin: Springer-Verlag, 1999.

22 Nakanishi Y, Ochiai A, Akimoto S, et al. Expression of E-cadherin, alpha-catenin, beta-catenin and plakoglobin in esophageal carcinomas and its prognostic significance: immunohistochemical analysis of 96 lesions. Oncology 1997;54:158-65.

23 Hirvikoski P, Kumpulainen E, Virtaniemi J, et al. p53 expression and cell proliferation as prognostic factors in laryngeal squamous cell carcinoma. f Clin Oncol 1997;15: 3111-20.

24 Pirinen R, Hirvikoski P, Böhm J, et al. Reduced expression of CD44v3 variant isoform is associated with unfavorable outcome in non-small cell lung cancer. Hum Pathol 2000;9: 1088-95.

25 Bagutti C, Speight PM, Watt FM. Comparison of integrin, cadherin, and catenin expression in squamous cell carcinomas of the oral cavity. F Pathol 1998;186:8-16.

26 Shiozaki $\mathrm{H}$, Iihara $\mathrm{K}$, Oka $\mathrm{H}$, et al . Immunohistochemical detection of alpha-catenin expression in human cancers. Am f Pathol 1994;144:667-74.

27 Hirvikoski P, Kumpulainen EJ, Virtaniemi JA, et al. Cytoplasmic accumulation of alpha-catenin is associated with aggressive features in laryngeal squamous-cell carciwith aggressive features in laryngeal

28 Krishnadath KK, Tilanus HW, van Blankenstein M, et al. Reduced expression of the cadherin-catenin complex in oesophageal adenocarcinoma correlates with poor prognosis. F Pathol 1997;182:331-8.

29 Shimazui T, Schalken JA, Giroldi LA, et al. Prognostic value of cadherin-associated molecules (alpha-, beta-, and gamma-catenins and p120cas) in bladder tumors. Cancer Res 1996;56:4154-8.

30 Sulzer MA, Leers MPG, van Noord AA, et al. Reduced E-cadherin expression is associated with increased lymph node metastases and unfavorable prognosis in non-small cell lung cancer. Am $\mathcal{F}$ Respir Crit Care Med 1998;157: 1319-23.

31 Ashida K, Terada T, Kitamura Y, et al. Expression of E-cadherin, alpha-catenin, beta-catenin, and CD44 (standard and variant isoforms) in human cholangiocarcinoma: an immunohistochemical study. Hepatology 1998;27:97482 .

32 Nhieu JT, Renard CA, Wei Y, et al. Nuclear accumulation of mutated beta-catenin in hepatocellular carcinoma is associated with increased cell proliferation. Am f Pathol 1999;155:703-7.

33 Pukkila MJ, Virtaniemi JA, Kumpulainen EJ, et al. Nuclear $\beta$-catenin expression is related to unfavourable outcome in oropharangeal and hypopharyngeal squamous cell carcinoma. 7 Clin Pathol 2001;54:42-7.

34 Gunther K, Brabletz T, Kraus C, et al. Predictive value of nuclear beta-catenin expression for the occurrence of distant metastases in rectal cancer. Dis Colon Rectum 1998; 41:1256-61.

35 Gunji N, Oda T, Todoroki T, et al. Pancreatic carcinoma: correlation between E-cadherin and alpha-catenin expression status and liver metastasis. Cancer 1998;82:1649-56. 